\title{
Pemberdayaan Masyarakat Dusun Padasan Desa Darsono Kecamatan Arjasa melalui Posdaya dan Produk Berbasis Rimpang Tanaman Obat
}

\author{
Endah Puspitasari, Viddy Agustian Rosyidi \\ Fakultas Farmasi Universitas Jember \\ Jl. Kalimantan No. 37 Jember \\ e.puspitasari@unej.ac.id
}

\begin{abstract}
Abstrak
Kelompok ibu-ibu di di Dusun Padasan belum memiliki aktivitas yang produktif, padahal mereka memiliki peluang dengan mengoptimalkan budidaya rimpang yang telah dilakukan dalam skala rumah tangga. Program Pengabdian Kemitraan (PPK) ini dilakukan dengan kelompok ibu-ibu di Dusun Padasan, Desa Darsono, Kecamatan Arjasa sebagai mitra. Pemberdayaan dilakukan dengan melatih dan mendampingi kelompok ibu-ibu di sana agar mampu menghasilkan bahan baku jamu berupa rimpang kunyit, jahe, dan temu kunci sesuai dengan kaidah Cara Pembuatan Obat Tradisional yang Baik (CPOTB) serta diversifikasi produk berbasis rimpang tanaman obat, yaitu kunyit, jahe, dan temu kunci. Hal ini dimaksudkan untuk mendukung program Saintifikasi Jamu yang telah dicanangkan pemerintah. Pelatihan yang diberikan adalah pelatihan tentang struktur organisasi dan tata kelola Posdaya; budidaya rimpang dan khasiatnya; pembuatan obat tradisional yang baik; serta pemasaran produk yang telah dihasilkan. Di akhir kegiatan, telah terbentuk Posdaya Darsono yang memiliki 3 jenis produk awal berbasis rimpang, yaitu teh herbal Wedang Uwuh, Jahe, dan Temulawak.
\end{abstract}

Kata kunci: pemberdayaan masyarakat Dusun Padasan, Posdaya, produk berbasis rimpang tanaman obat

\begin{abstract}
The group of mothers in Dusun Padasan does not have productive activities yet, eventhough they have the opportunity to optimize the cultivation of rhizomes that have been carried out at the household scale. The Partnership Service Program (PPK) was conducted with a group of women in Dusun Padasan, Desa Darsono, Kecamatan Arjasa as partners. Empowerment was done by training and assisting groups of mothers to be able to produce herbal raw materials in the form of turmeric, ginger, and temu kunci meeting the criteria of Good Traditional Medicine Manufacturing (CPOTB) and diversification of medicinal rhizome-based products, namely turmeric, ginger, and temu kunci. These programs were intended to support the Saintification of Herbal Medicine program launched by the government. The training provided were training on Posdaya organizational structure and governance; rhizome cultivation and its properties; making good traditional medicine; and marketing the products that have been produced. At the end of the activity, Posdaya Darsono was formed. They had 3 types of rhizome-based initial products, namely Wedang Uwuh, Ginger and Temulawak herbal tea.
\end{abstract}

Keywords: community development in Dusun Padasan, Posdaya, medicinal plants rhizomebased products 


\section{PENDAHULUAN}

Dusun Padasan, Desa Darsono, Kecamatan Arjasa, Kabupaten Jember terletak di ujung barat kota Jember dengan jumlah warga sekitar 55 kepala keluarga. Mayoritas masyarakat Dusun Padasan bekerja sebagai petani, buruh, dan kerja serabutan, sehingga pendapatan mereka tergolong rendah. Kondisi ini diperparah dengan rendahnya kemampuan literasi dan teknologi dari masyarakat Dusun Padasan. Banyak masyarakat Dusun Padasan menganggap bahwa pendidikan formal bukanlah hal yang perlu diutamakan. Tidaklah heran jika mereka lebih banyak bekerja di bidang informal. Meskipun hampir di setiap rumah memiliki hewan ternak seperti sapi dan kambing, namun tidak ada yang memiliki ternak dalam jumlah besar, sehingga hal ini tidak terlalu berpengaruh pada penghasilannya (Yayuk, 2019).

Potensi Dusun Padasan di bidang pertanian merupakan aset yang penting, namun masih banyak ditemukan beberapa lahan dan ruang terbuka yang belum dimanfaatkan dengan optimal, padahal kondisi tanah lahan-lahan tersebut baik dan subur. Salah satu pemanfaatan lahan terbuka oleh masyarakat di Dusun Padasan adalah budidaya rimpang, khususnya kunyit, jahe, dan temu kunci. Semuanya ditanam untuk digunakan sendiri, baik sebagai bumbu masak maupun sebagai bahan baku jamu. Budidaya rimpang dilakukan oleh ibu-ibu di Dusun Padasan. Sebagai masyarakat dengan pekerjaan utama bertani, tentu mereka tidak mengalami kesulitan dalam melakukan budidaya rimpang tersebut (Yayuk, 2019).

Budidaya rimpang ini masih dapat dioptimalkan, karena masih banyak lahan kosong yang belum dimanfaatkan. Ibu-ibu di Dusun Padasan belum memiliki aktivitas yang produktif. Aktivitas rutin dari mayoritas ibu-ibu di Dusun Padasan adalah mencari rumput di pagi hari dan aktivitas sebagai ibu rumah tangga. Kalaupun ada kegiatan lain, hanyalah kegiatan sosial berupa perkumpulan pengajian, dll (Yayuk, 2019).

Di sisi lain, pemerintah sedang menggalakkan program Saintifikasi Jamu yang telah dicanangkan melalui Peraturan Menteri Kesehatan Republik Indonesia Nomor: 003/Menkes/Per/I/2010 tahun 2010 tentang Saintifikasi Jamu dalam Penelitian Berbasis Pelayanan Kesehatan (Kemenkes RI, 2010). Beberapa instansi pemerintah maupun swasta telah melaksanakan program ini, namun mereka terkendala dengan bahan baku jamu yang digunakan. Selama ini, stok bahan baku jamu, termasuk rimpang, diperoleh dari Balai Besar Penelitian dan Pengembangan Tanaman Obat dan Obat Tradisional (B2P2TOOT). Namun, karena kebutuhan yang tinggi, B2P2TOOT tidak dapat memenuhi semua permintaan yang ada (B2P2TOOT, 2016).

Hal ini menjadi peluang bagi masyarakat di Dusun Padasan, khususnya dalam pemberdayaan ibu-ibu yang secara alamiah lebih telaten, terampil, dan bekerja dengan sangat hati-hati (Bhastoni dan Yuliati, 2015). Terlebih, pemerintah melalui Peraturan Menteri Kesehatan Republik Indonesia Nomor: 88 tahun 2013 tentang Rencana Induk Pengembangan Bahan Baku Obat Tradisional berusaha melibatkan Usaha Kecil Obat Tradisional (UKOT) dan Usaha Mikro Obat Tradisional (UMOT) dalam alur pikir penyusunan Rencana Induk Pengembangan Bahan Baku Obat Tradisional (Kemenkes RI, 2013). 
Program Pengabdian Kemitraan (PPK) ini dilakukan dengan kelompok ibu-ibu di Dusun Padasan, Desa Darsono, Kecamatan Arjasa sebagai mitra. Pemberdayaan dilakukan dengan melatih dan mendampingi kelompok ibu-ibu di sana agar mampu menghasilkan bahan baku jamu berupa rimpang kunyit, jahe, dan temu kunci sesuai dengan kaidah Cara Pembuatan Obat Tradisional yang Baik (CPOTB) serta diversifikasi produk berbasis rimpang tanaman obat, yaitu kunyit, jahe, dan temu kunci. Di awal, dilakukan pendampingan untuk membentuk Posdaya beserta struktur organisasi agar kelompok ibu-ibu di Dusun Padasan dapat lebih terorganisir dan lebih mandiri. Dengan program ini diharapkan mitra akan menjadi kelompok yang produktif dan dapat menambah penghasilan keluarga, sedangkan terbentuknya Posdaya lengkap dengan struktur organisasinya diharapkan dapat menjaga keberlangsungan program ini ke depan.

\section{METODE PELAKSANAAN KEGIATAN}

Metode yang digunakan untuk mengatasi permasalahan pada mitra adalah penyuluhan, pelatihan, dan pendampingan mengenai solusi yang ditawarkan tim pelaksana kepada mitra. Selain itu, juga diberikan tambahan modal berupa timbangan gram, alat perajang, pengering, penggiling, dan sealer yang layak dan memadai sehingga dapat dijadikan modal dalam usaha berbasis rimpang tanaman obat. Metode yang digunakan meliputi partisipatoris (tim pelaksana bersama dengan mitra merumuskan masalah dan merancang program untuk menyelesaikan masalah), pendampingan oleh tim pelaksana kepada mitra, dan pemberian modal usaha dalam bentuk peralatan yang dibutuhkan untuk memecahkan masalah yang ada.

Format solusi yang ditawarkan adalah dalam bentuk kegiatan pelatihan dan pendampingan. Pelatihan dilakukan dengan metode ceramah (penyuluhan), diskusi dan praktek, dengan menggunakan alat bantu berupa viewer, alat peraga, dan contoh-contoh yang diperlukan. Materi pelatihan dapat dilihat pada Tabel l. Sedangkan pendampingan dilakukan dengan supervisi penerapan keterampilan yang diberikan dalam pelatihan untuk memastikan bahwa keterampilan yang diberikan benar-benar diimplementasikan di lapangan. Dampak dari segi ekonomi yang diharapkan dari kegiatan ini yaitu meningkatnya pendapatan dan kesejahteraan kelompok ibu-ibu Dusun Padasan, Desa Darsono, Kecamatan Arjasa. Pemberdayaan dilakukan dengan terlebih dahulu membentuk Posdaya, sehingga ke depan diharapkan masyarakat Dusun Padasan dapat mandiri dan tidak tergantung tim pelaksana. Tim pelaksana hanya berfungsi sebagai inisiator dan fasilitator saja. Selain dampak ekonomi, dampak bidang IPTEK yang diharapkan yaitu terjadinya transfer ilmu (alih teknologi) antara perguruan tinggi dengan masyarakat dan terbentuknya sinergi dengan pihak terkait demi keberlangsungan program ini. 
Tabel l. Materi pelatihan yang diberikan

\begin{tabular}{|l|l|}
\hline \multicolumn{1}{|c|}{ Pelatihan } & \multicolumn{1}{|c|}{ Materi } \\
\hline $\begin{array}{l}\text { Struktur organisasi dan tata kelola } \\
\text { Posdaya }\end{array}$ & $\begin{array}{l}\text { Pengertian Posdaya, struktur organisasi dan tata } \\
\text { kelola Posdaya, pembentukan pengurus Posdaya }\end{array}$ \\
\hline Budidaya rimpang dan khasiatnya & $\begin{array}{l}\text { Cara budidaya rimpang yang baik (bibit hingga } \\
\text { pemanenan), khasiat rimpang yang ditanam (kunyit, } \\
\text { jahe, temu kunci) }\end{array}$ \\
\hline $\begin{array}{l}\text { Pembuatan obat tradisional yang } \\
\text { baik }\end{array}$ & $\begin{array}{l}\text { Proses pasca panen, pembuatan simplisia yang baik, } \\
\text { kontrol kualitas sederhana, pembuatan produk- } \\
\text { produk terpilih (simplisia dan serbuk dalam } \\
\text { kemasan celup) }\end{array}$ \\
\hline $\begin{array}{l}\text { Pemasaran produk yang telah } \\
\text { dihasilkan }\end{array}$ & $\begin{array}{l}\text { Cara pemasaran produk, cara menjalin hubungan } \\
\text { dengan stakeholder, praktek pemasaran }\end{array}$ \\
\hline
\end{tabular}

Simplisia adalah bahan alami yang digunakan untuk obat dan belum mengalami perubahan proses apa pun, dan kecuali dinyatakan lain umumnya berupa bahan yang telah dikeringkan (Depkes RI, 1979).

\section{HASIL DAN PEMBAHASAN}

Pelaksanaan kegiatan PPK ini diawali dengan koordinasi antara tim pelaksana dengan mitra untuk menyamakan persepsi dan memetakan kembali dengan lebih detail kegiatan-kegiatan yang diselenggarakan beserta jadwalnya masing-masing. Koordinasi ini dilakukan segera setelah ada pengumuman bahwa program pengabdian kepada masyarakat ini didanai. Koordinasi dilakukan di rumah Ibu Yayuk, ketua paguyuban ibuibu Dusun Padasan, Desa Darsono, Kecamatan Arjasa dan dihadiri oleh beberapa ibu-ibu yang aktif dalam paguyuban tersebut.

Agenda selanjutnya adalah pembentukan Posdaya. Semua anggota ibu-ibu paguyuban diundang untuk diberikan sosialisasi mengenai program pengabdian kemitraan ini beserta kegiatan-kegiatan yang dilakukan. Pada kesempatan ini juga dijelaskan bahwa untuk menjamin kelangsungan kegiatan ini perlu dibentuk organisasi yang definitif dengan kepengurusan yang jelas. Organisasi ini merupakan gerakan pemberdayaan masyarakat, karenanya tepat jika dibuat dalam bentuk Posdaya. Di awal, diberikan gambaran mengenai pengertian Posdaya beserta contoh-contoh struktur organisasi dan tata kelola. Dijelaskan juga mengenai tugas pokok dan fungsi (tupoksi) dari setiap jabatan yang ada. Setelah berdiskusi dengan panjang lebar, diputuskan untuk menggunakan nama Posdaya Darsono dengan struktur organisasi Posdaya seperti yang tertera pada Gambar 1. Dengan terbentuknya Posdaya ini, telah jelas siapa yang bertanggung jawab dengan tupoksi masing-masing, sehingga diharapkan organisasi dapat berjalan dengan baik.

Kegiatan selanjutnya adalah penyuluhan mengenai budidaya rimpang dan khasiatnya. Penyuluhan dilakukan pada tanggal 1 September 2019 di mushollah Dusun Padasan, Desa Darsono, Kecamatan Arjasa. Sehari sebelumnya dilakukan koordinasi untuk memastikan pelaksanaan penyuluhan. Pada penyuluhan ini disampaikan materi 
mengenai cara budidaya rimpang yang baik, mulai dari bibit hingga pemanenan. Selain itu disampaikan juga informasi mengenai khasiat rimpang yang ditanam. Rimpang dipilih karena kebanyakan budidaya yang dilakukan oleh ibu-ibu anggota Posdaya Darsono adalah rimpang, misalnya kunyit, jahe, dan temu kunci.

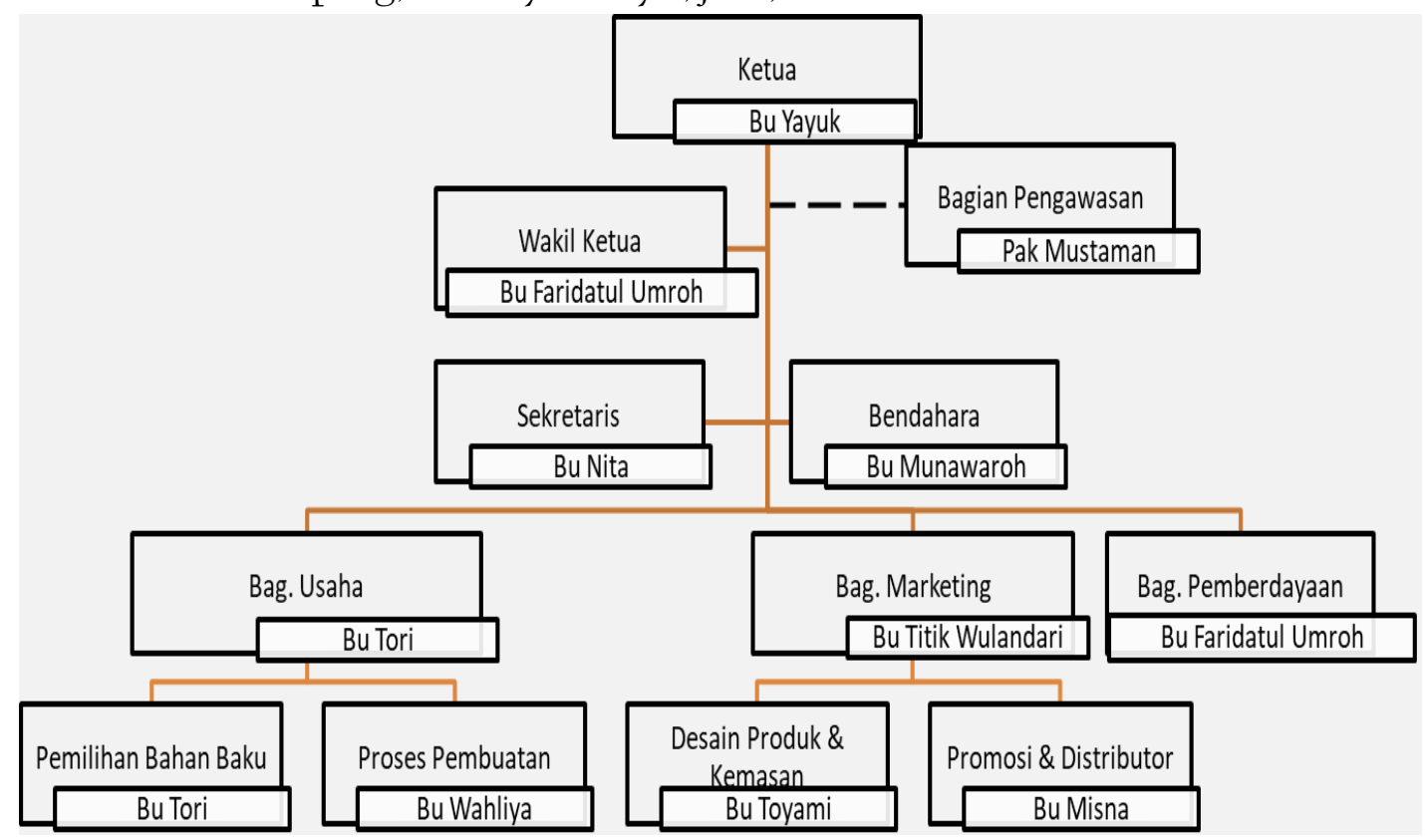

Gambar 1. Struktur organisasi dan tata kerja Posdaya Darsono

Pelatihan pembuatan obat tradisional yang baik dilakukan di MI Baitul Muta'allim Barokatul Kholili Dusun Padasan, Desa Darsono, Kecamatan Arjasa. Seperti biasa, koordinasi persiapan kegiatan di mitra dilakukan sebelum kegiatan. Pelatihan yang diberikan kepada mitra adalah proses pasca panen, pembuatan simplisia yang baik, kontrol kualitas sederhana (termasuk ciri-ciri simplisia kering, bagaimana mengetahui adanya cemaran jamur secara sederhana), serta pembuatan produk-produk terpilih baik pembuatan simplisia maupun serbuk dalam kemasan celup. Optimasi formulasi dilakukan oleh tim pelaksana sebelum kegiatan pelatihan dilangsungkan. Mitra juga diberi pengetahuan bagaimana melakukan optimasi formula produk teh herbal. Mitra melakukan praktek semua alur produksi teh herbal, mulai dari mencuci rimpang, sortasi basah, pembuatan simplisia, penyerbukan, hingga membuat formula dan mengemas produk. Selanjutnya peserta juga melakukan uji organoleptis produk yang dihasilkan, sehingga nanti dapat digunakan sebagai bekal dalam proses kontrol kualitas produk secara sederhana. Produk yang pertama kali dikembangkan terdiri dari 3 jenis, seperti yang tertera pada Gambar 2.

Pada kesempatan ini pula, dilakukan serah terima bantuan modal berupa timbangan gram sebanyak 2 buah, alat perajang sebanyak 4 buah, alat pengering (oven) sebanyak 2 buah, whiteboard sebanyak 1 buah, penggiling sebanyak 3 buah, sealer sebanyak 2 buah, dan kain hitam sebanyak 4 m (Gambar 3). Kain hitam digunakan sebagai penutup saat mengeringkan rimpang yang sudah dirajang hingga menjadi simplisia agar bahan tidak terkena sinar uv dari matahari secara langsung, agar kualitas senyawa aktif 
dalam bahan tidak rusak, serta melindungi bahan dari debu dan kotoran. Oven digunakan di saat simplisia masih lembab namun tidak dapat kering lagi, misalkan karena cuaca sudah mulai mendung dan masuk musim penghujan. Sedangkan whiteboard dapat digunakan untuk kegiatan rapat dan diskusi Posdaya Darsono.

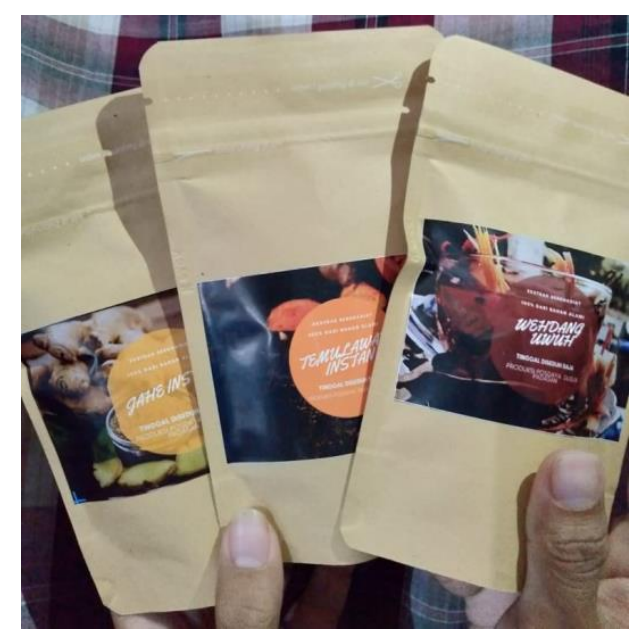

Gambar 2. Produk teh herbal Posdaya Darsono
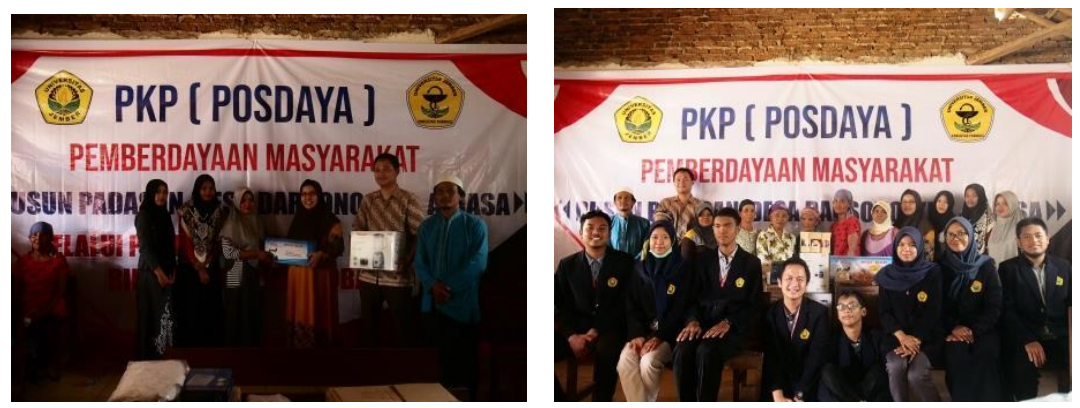

Gambar 3. Serah terima bantuan modal berupa alat kepada Posdaya Darsono

Kegiatan keempat adalah pemasaran produk yang telah dihasilkan. Mitra diberi pengetahuan mengenai cara pemasaran produk, menjalin hubungan dengan stakeholder, dan praktek pemasaran. Penyuluhan mengenai materi ini diberikan kepada pengurus Posdaya Darsono. Pada saat penyuluhan tersebut, juga dilakukan pendampingan kepada pengurus untuk membuat logo dan laman sosial media untuk publikasi kegiatan Posdaya Darsono dan pemasaran produk-produk mereka. Logo Posdaya Darsono dapat dilihat pada Gambar 4 dan laman tersebut dapat diakses pada link https://www.instagram.com/posdayadarsonosherbs/ (Gambar 5). 


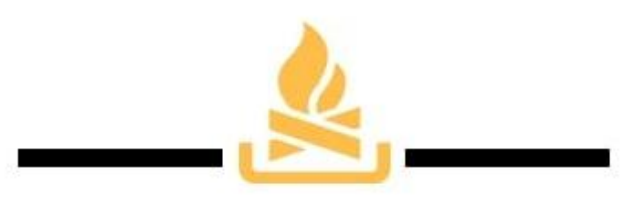

\section{DARSONO'S}

\section{TEA AND HERBS}

Gambar 4. Logo Posdaya Darsono

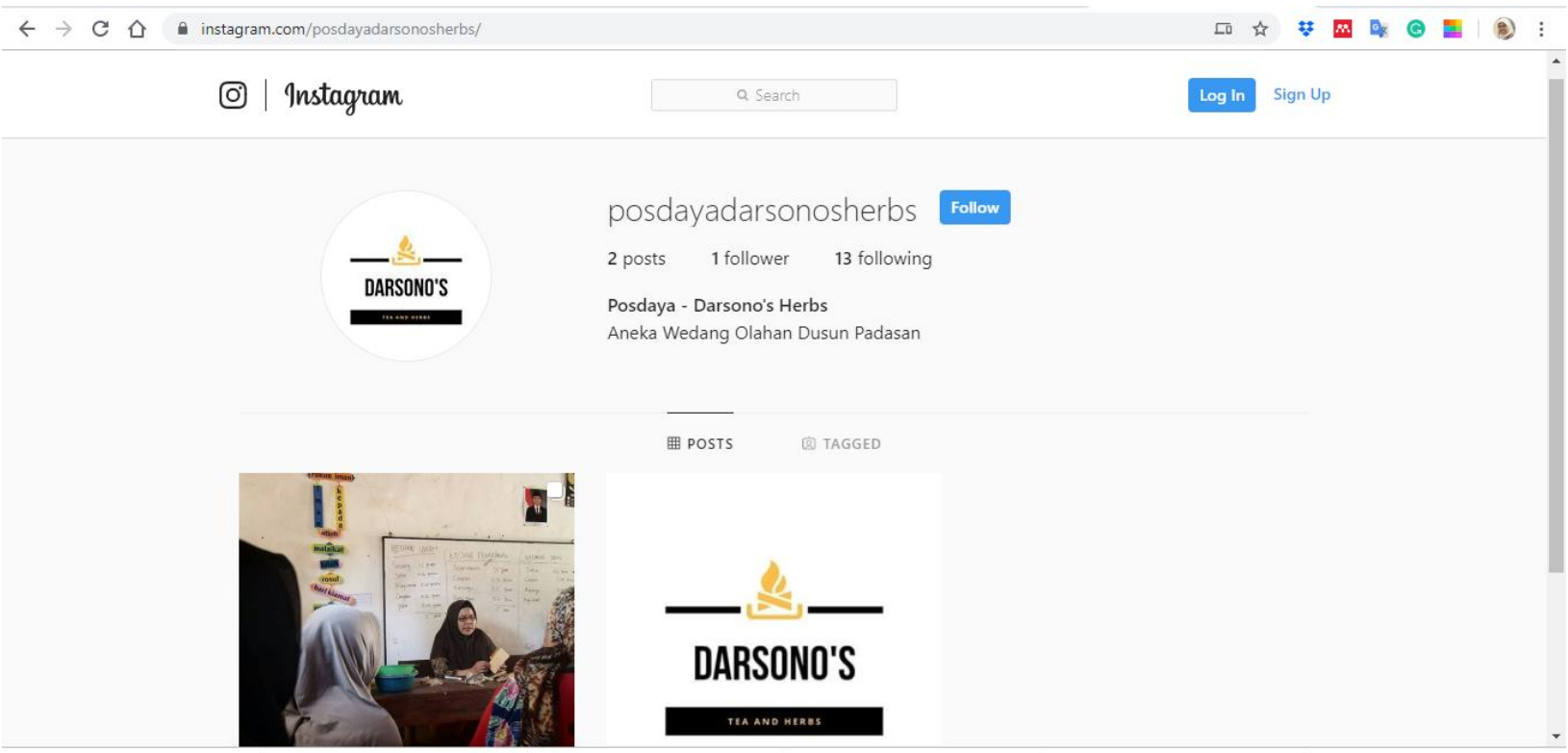

Gambar 5. Tampilan sosial media Instagram Posdaya Darsono

Meskipun kegiatan ini baru dirintis, ternyata Posdaya Darsono dapat memanfaatkan momentum yang ada. Pada minggu ketiga bulan Oktober 2019, ada pertemuan besar di Desa Darsono, mereka membuat produk, mengenalkan dan memasarkan produk mereka di forum tersebut. Hal ini menunjukkan bahwa antusiasme pengurus dapat terus terjaga dengan baik.

\section{PENUTUP}

Pengabdian kepada masyarakat ini berlangsung dengan lancar dan mendapat dukungan dari masyarakat di Dusun Padasan Desa Darsono Kecamatan Arjasa. Semua program telah berjalan dengan baik. Bantuan modal dapat berfungsi dengan baik. Pelatihan dan pendampingan juga telah berjalan, bahkan halaman di sosial media mengenai Posdaya Darsono juga telah dibuat. 


\section{UCAPAN TERIMA KASIH}

Penulis mengucapkan terima kasih kepada Universitas Jember atas pendanaan yang diberikan melalui Progam Pengabdian Kemitraan tahun 2019.

\section{DAFTAR PUSTAKA}

B2P2TOOT, 2016. Laporan Tahunan 2015. Balai Besar Penelitian dan Pengembangan Tanaman Obat dan Obat Tradisional.

Bhastoni K dan Yuliati Y, 2015. Peran Wanita Tani di Atas Usia Produktif dalam Usahatani Sayuran Organik terhadap Pendapatan Rumah Tangga di Desa Sumberejo Kecamatan Batu. Habitat 26 (2): 119-129.

Depkes RI, 1979. Farmakope Indonesia Edisi III. Departemen Kesehatan Republik Indonesia. Kemenkes RI, 2010. Peraturan Menteri Kesehatan Republik Indonesia Nomor: 003/Menkes/Per/I/2010 tahun 2010 tentang Saintifikasi Jamu dalam Penelitian Berbasis Pelayanan Kesehatan. Kementerian Kesehatan Republik Indonesia.

Kemenkes RI, 2013. Peraturan Menteri Kesehatan Republik Indonesia Nomor: 88 tahun 2013 tentang

Rencana Induk Pengembangan Bahan Baku Obat Tradisional. Kementerian Kesehatan Republik Indonesia.

Yayuk, 2019. Kondisi Masyarakat Dusun Padasan, Desa Darsono, Kecamatan Arjasa, Kabupaten Jember. Hasil Wawancara Pribadi, 2 Mei 2019. 